
\title{
$\angle$ Research Suare \\ Estrogen inhibits apoptosis of pericytes in the cochlea stria vascularis through downregulating TMEM16A
}

\section{Xuerui Li}

Medical College of Shihezi University https://orcid.org/0000-0002-4313-5808

\section{Yang Zhang}

Jining Medical University Affiliated Hospital

\section{Long Chen}

Shihezi University School of Medicine

\section{Ziyi Feng}

Shihezi University School of Medicine

\section{Ketao Ma}

Shihezi University School of Medicine

Li Li ( $\square$ Lily7588@163.com )

https://orcid.org/0000-0001-8591-0676

\section{Junqiang Si}

Shihezi University School of Medicine

\section{Research article}

Keywords: TMEM16A, pericytes, presbycusis, estrogen, apoptosis

Posted Date: August 20th, 2020

DOl: https://doi.org/10.21203/rs.3.rs-20853/v2

License: (9) This work is licensed under a Creative Commons Attribution 4.0 International License. Read Full License 


\section{Abstract}

Background: Currently, the specific mechanism of estrogen (E2) in protecting presbycusis is not clear. This study aimed to investigate whether E2 could affect the apoptosis of capillary pericytes (PCs) of cochlear stria vascularis (SV) in aged C57BL/6J mice by regulating transmembrane member $16 \mathrm{~A}$ (TMEM16A), such that it plays a protective role in presbycusis.

Methods: The model of C57BL/6J ovariectomized mice was established, and E2 was administered for 2 months. The hearing threshold was measured by auditory brainstem response (ABR). The changes in the cochlea were measured using hematoxylin-eosin (HE) and electron microscopy. qRT-PCR was used to examine the expression of TMEM16A and apoptosis-related protein mRNA. The PCs were cultured in vitro, and the cell senescence model was established by the continuous passage method. TMEM16A expression was assessed using immunofluorescence. Flow cytometry was performed to explore the apoptosis rate.

Results: The results of animal experiments showed that E2 intervention could reduce hearing loss and improve the atrophy of cochlear SV, loss of PC chromatin organelles, cytoplasmic swelling and nuclear porosity in aged mice. E2 also decreased the mRNA expression of TMEM16A, Caspase-3 and Bax in cochlear SV of aged mice and upregulated the expression of Bcl-2 mRNA. Cellular experiments showed that E2 could downregulate the expression of TMEM16A, and E2 or T16Ainh-A01(a specific blocker of TMEM16A) could reduce the apoptosis rate of PCs in aged mice.

Conclusions: E2 may inhibit the apoptosis of PCs through downregulating the expression of TMEM16A, which plays a protective role in presbycusis. This study may provide a novel potential treatment and prevention method for presbycusis.

\section{Introduction}

With the aging of the population, organs age and change in function, and the number of patients with presbycusis is increasing(Ciorba et al. 2015). Presbycusis seriously affects the quality of life of the elderly, the effective use of hearing aids is beneficial to this population, improving their quality of life and health conditions(Carniel et al. 2017). To date, the specific pathogenesis of presbycusis has not been clear. Age-related deterioration of the stria vascularis (SV) is one of the main causes of presbycusis(Gratton et al. 1996;Spicer and Schulte 2005). Pericytes (PCs) play an important role in maintaining SV homeostasis(Shi et al. 2008). Some studies have shown that the abnormal PCs in the cochlea can cause capillary leakage and lead to hearing loss(Shi 2009). Although the mechanism of these phenomena is still unclear, the data suggest that PCs may be a new direction for the prevention and treatment of presbycusis.

There are gender differences in the damage of presbycusis, with men developing presbycusis earlier than women(Helzner et al. 2005;Park et al. 2016), and estrogen (E2) replacement therapy can delay presbycusis(Hederstierna et al. 2007; Williamson et al. 2020). Some studies have shown that E2 is related 
to apoptosis. E2 not only can reduce apoptosis of vascular smooth muscle cells(Ling et al. 2004) but can also reduce the apoptosis of cochlear outer hair cells induced by gentamicin ototoxicity, which is achieved by inhibiting the JNK pathway(Nakamagoe et al. 2010). However, the specific mechanism of E2 in protecting presbycusis is not clear.

Transmembrane member 16A (TMEM16A)-encoded $\mathrm{Ca}^{2+}$-activated $\mathrm{Cl}^{-}$channels play a variety of physiological roles in many organs and tissues(Yang et al. 2008). Accumulating evidence shows that TMEM16A is closely related to many cells in the cochlea(Jeon et al. 2011;Wang et al. 2015;Zhang et al. 2015), and previous research by our research team showed that TMEM16A exhibits age-related changes in cochlear SV PCs(Zhou et al. 2019). It has been confirmed that autophagy and apoptosis are increased in presbycusis mice(Menardo et al. 2012). However, whether the effect of TMEM16A on SV PC apoptosis in presbycusis has not yet been reported.

Currently, the specific mechanism of E2 in presbycusis is not clear. Based on the protective effect of E2 on cochlear cell apoptosis, this study aimed to explore whether E2 can inhibit the apoptosis of PCs in cochlear SV through regulating the expression of TMEM16A. Our research results have laid an experimental foundation for elucidating the potential mechanism of E2 regulating auditory function and have provided new strategies for the prevention and treatment of presbycusis.

\section{Materials And Methods}

\section{Experimental grouping and treatment}

Animals were provided by the Animal Experiment Center of Beijing Vital River Laboratory Animal Technology Co. (animal use license batch no. SCXK Beijing 2016-0006). The use of animals in the present study was approved by the Committee of Animal Experimental Ethics of The First Affiliated Hospital of Medical College, Shihezi University (permit no. A2018-160-01). A total of 40 C57BL/6J female mice were divided into the following four groups (10/group): 3-month-old (3 m) group, 12-month-old (12 $\mathrm{m}$ ) group, 12-month-old ovariectomized (12 m OVX) group (OVX at the age of 9 months) and $12 \mathrm{~m} \mathrm{OVX}$ group treated with E2 (OVX at the age of 9 months and after 1 month treated with E2 $[0.10 \mathrm{mg} / \mathrm{kg} / \mathrm{d}]$ until the age of 12 months(Wu et al. 2016)).

Cell-based experiments were divided into a group of $5^{\text {th }}$-generation (P5) PCs, a group of $13^{\text {th }}$-generation (P13) PCs, a group of P13 PCs given DMSO, a group of P13 PCs given E2 (treated with $10^{-8} \mathrm{mmol} / \mathrm{L}$ E2 for $24 \mathrm{~h}$ ), a group of P13 PCs given T16Ainh-A01 (treated with $30 \mu \mathrm{mol} / \mathrm{L}$ T16Ainh-A01 for $24 \mathrm{~h}$ ), and a group of P13 PCs given T16Ainh-A01 and E2 (treated with $30 \mu \mathrm{mol} / \mathrm{L}$ T16Ainh-A01 for $24 \mathrm{~h}$ and then treated with $10^{-8} \mathrm{mmol} / \mathrm{L}$ E2 for $24 \mathrm{~h}$ ).

\section{Auditory brainstem response (ABR) detection}

C57BL/6J mice were anesthetized by intraperitoneal injection and were placed in a soundproof screening room. Three platinum needle electrodes were placed subdermally at the vertex (positive electrode), the left 
mastoid (negative electrode) and right hind leg (ground electrode). ABR waves were recorded in response to a series of click stimuli. The intensity of acoustic stimulation was 30-100 dB SPL, the scanning time was $10 \mathrm{sec}$, and the number of superimposed stimuli was 1,024. The stimulation protocol included stimulus intervals of 11.10 beats/sec. The intensity of each stimulus decreased every $20 \mathrm{~dB}$ SPL. When approaching the threshold, the decrease was every $5 \mathrm{~dB}$ SPL. The amplitude and threshold changes of ABR III waves in each group were observed.

\section{Hematoxylin-eosin staining}

The bilateral temporal bones of mice were immersed in $4 \%$ paraformaldehyde solution. The cochlea in all groups were decalcified in $10 \%$ EDTA $\left(25^{\circ} \mathrm{C}\right)$ for 7 days. Then, the cochlea was embedded in paraffin so that its orientation was parallel to the cochlear axis. A microtome was then used to section the tissues at a thickness of $3 \mu \mathrm{m}$. Finally, the sections were stained with HE, analyzed by light microscopy and then photographed (BX43, Olympus, JPN).

\section{Transmission electron microscopy (TEM)}

The cochlear segments of the mice were fixed overnight in phosphate-buffered $3 \%$ glutaraldehyde, and the cochlear tissue was then cut into $1 \mathrm{~mm} \times 1 \mathrm{~mm} \times 1 \mathrm{~mm}$ pieces and postfixed in $1 \%$ osmium. Then, the osmium was flushed from the tissue, and it was dehydrated, saturated and embedded in Epon 812 epoxy resin. An LKB-2188 ultrathin slicer was used to generate sections, and uranium dioxide acetate and lead citrate double electron staining was performed. Observation and photography were performed using a transmission electron microscope (JEM-1230, JEOL, JPN).

\section{Reverse transcription-quantitative PCR}

Total RNA was extracted from mice cochlear SV tissues using an RNeasy Mini Kit, and the RNA was predenatured at $70^{\circ} \mathrm{C}$ for $5 \mathrm{~min}$, annealed at $42^{\circ} \mathrm{C}$ for $60 \mathrm{~min}$, and extended at $4^{\circ} \mathrm{C}$ for $5 \mathrm{~min}$ to generate cDNA through reverse transcription. Then, the target gene and internal reference were amplified. The following primers were used for qPCR amplification: $\beta$-actin, forward 5'-ACTGCTCTGGCTCCTAGCAC-3', reverse 5'-ACATCTGCTGGAAGGTGGAC-3'; TMEM16A, forward 5'-CACTCTTCGCCCTGCTAAAC-3', reverse 5'-ACCAGATGCCGATGTCTTTG-3'; Bax, forward 5'-TGAAGACAGGGGCCTTTTTG-3', reverse 5'AATTCGCCGGAGACACTCG-3'; Bcl-2, forward 5'-ACGGTGGTGGAGGAACTCTTCAG-3', reverse 5'GGTGTGCAGATGCCGGTTCAG-3'; and Caspase-3, forward 5'-TGGTGATGAAGGGGTCATTTATG-3', reverse 5'-TTCGGCTTTCCAGTCAGACTC-3'. The thermocycling conditions consisted of 2 min of hot-start enzyme activation at $95^{\circ} \mathrm{C}$, which was followed by 40 cycles of PCR at $95^{\circ} \mathrm{C}$ for $5 \mathrm{sec}$ (denaturation), $60^{\circ} \mathrm{C}$ for 40 sec (annealing) and $72^{\circ} \mathrm{C}$ for $30 \mathrm{sec}$ (elongation). The mRNA expression level was calculated by the $2^{-}$ $\triangle \triangle \mathrm{CT}$ method.

\section{Primary culture of PCs}


Primary cell culture was performed as described above, with some modifications(Zhang et al. 2017). Using C57BL/6J mice aged 8-11 days $(n=3)$, cochlear tissues were removed under sterile conditions and were soaked in $4^{\circ} \mathrm{C}$ D-Hanks solution. The SV was gently separated under a dissecting microscope and transferred to $0.7 \mathrm{~mL}$ of cell culture medium. Next, the SV was minced into $0.15-0.20-\mathrm{mm}^{3}$ pieces, and the pieces were evenly arranged on the bottom surface of the culture dish using sterile ophthalmology. Tissues were incubated at $37^{\circ} \mathrm{C}$ in an atmosphere containing $5 \% \mathrm{CO}_{2}$. After $24 \mathrm{~h}, 1 \mathrm{~mL}$ of cell culture solution was carefully added. On day 3 , the unattached fragments were washed with phosphate-buffered saline, and new cell culture solution was added. After 2 - 3 washes per week, the PCs were purified by digestion passage.

\section{Immunofluorescence}

Immunofluorescence was used to identify the primary cultured PCs, which were fixed with $4 \%$ paraformaldehyde for $15 \mathrm{~min}$ after 3 days. Subsequently, the cells were incubated in 0.3\% Triton-100 (100 $\mu \mathrm{l}$ ) for $30 \mathrm{~min}$ and blocked in $5 \%$ bovine serum albumin (BSA; cat. no. B2064; Sigma-Aldrich; Merck $\mathrm{KGaA}$ ) at room temperature for $1 \mathrm{~h}$. Then, the cells were incubated with anti-desmin (1:100; cat. no. ab8470; Abcam) or a-SM-actin monoclonal antibody (1:100; cat. no. ab7817; Abcam) or anti-vWF (1:100; cat. no. Ab11713; Abcam) at $4^{\circ} \mathrm{C}$ overnight. The next day, slides were incubated with a FITC-conjugated goat anti-mouse secondary antibody (1:100, ZF-0312; OriGene Technologies, Inc.) at $37^{\circ} \mathrm{C}$ for 60 min. Nuclear staining was performed using DAPI (Solarbio Science and Technology Co.), and the cells were photographed by laser scanning confocal microscopy (Zeiss LSM 510 META, Carl Zeiss AG).

Immunofluorescence detection of TMEM16A expression was performed. The experimental steps were the same as those used to identify PC immunofluorescence but with the incubation of different antibodies. The slides were incubated with a rabbit anti-TMEM16A antibody $\left(1: 100 ;\right.$ cat. no. ab64085; Abcam) at $4^{\circ} \mathrm{C}$ overnight. The next day, slides were incubated with a FITC-conjugated goat anti-rabbit antibody $(1: 100$, ZF-0311; OriGene Technologies, Inc.) at $37^{\circ} \mathrm{C}$ for $1 \mathrm{~h}$.

\section{Cell aging model}

The cells of the 5th, 9th and 13th generations were placed in six-well plates and were cultured under standard conditions for $24 \mathrm{~h}$. A $\beta$-galactosidase staining kit (cat. no. C0602; Beyotime, Haimen, China) was then used according to the manufacturer's instructions, and $1 \mathrm{~mL}$ of $\beta$-galactosidase fixed solution was added to each well. After being fixed at room temperature for $15 \mathrm{~min}, 1 \mathrm{~mL}$ of working dye solution was added to each well. After the six-well plate was sealed with plastic wrap and incubated overnight in a $37^{\circ} \mathrm{C}$ incubator, the results were photographed under an ordinary optical microscope.

\section{Flow cytometry}

Trypsin digestion was used to collect the cells. Cells were centrifuged at $1000 \mathrm{rpm}$ for $6 \mathrm{~min}$ and then were washed twice with precooled PBS. Each tube contained $500 \mu \mathrm{L}$ of binding buffer, in which the cells were resuspended. Then, $5 \mu$ of Annexin V-FITC and $10 \mu$ of PI staining solution were added. After 
mixing, the cells were incubated in the dark for $30 \mathrm{~min}$. The resuspended liquid was transferred to a flow cytometry sample tube for machine detection.

\section{Statistical analysis}

Statistical analysis was performed using SPSS 19.0 software, and GraphPad Prism was used to generate graphs. All the results are expressed by (). Every data point was analyzed by one-way ANOVA. Results with $P$ values of less than 0.05 were considered statistically significant.

\section{Results}

\section{$A B R$ was detected in different groups of mice}

The change in the ABR III wave threshold was observed in each group (Fig. 1). The results of ABR showed that there was hearing loss in 12-month-old mice $\left({ }^{\star \star} P<0.01\right)$, and the hearing loss in ovariectomized mice was more obvious than that in 12-month-old mice $\left({ }^{\#} P<0.05\right)$. E2 intervention could alleviate this hearing loss $\left({ }^{\&} P<0.05\right)$.

Fig. 1 ABR threshold results of each group

The results are presented as the mean $\pm S D, n=10 .{ }^{* *} P<0.01$ vs. the 3 m group. ${ }^{\#} P<0.05$ vs. 12 m group. $\& P<0.05$ vs. the $12 \mathrm{~m}$ OVX group.

\section{Morphological observation of cochlear stria vascularis and pericytes}

HE staining was used to observe the morphological changes of cochlear SV (Fig. 2A). The structural changes of PCs were observed under TEM (Fig. 2B). In the $3 \mathrm{~m}$ group, the shape of cochlear SV was normal, the PCs had a good shape and the cytoplasmic and nuclear components were abundant. In the $12 \mathrm{~m}$ group, there was a large degree of vacuolar degeneration in the cochlear SV, loss of chromatin organelles and cytoplasmic swelling in PCs. In the $12 \mathrm{~m}$ OVX group, the cochlear SV was obviously atrophic, the cytoplasm was decreased, the PC chromatin organelles were lost, and the nucleus was loose. When treated with E2, the vacuolar degeneration decreased, the atrophy improved in the cochlear SV, the chromatin was dense and the cytoplasm was not swollen in PCs. These results suggest that E2 can improve the degeneration of SV and PCs in aged mice.

Fig. 2A HE staining of the cochlear SV in each group.

Fig. 2A1 to D1 (inverted microscope, $\times 100$ ) and Fig. 3A2 to D2 (inverted microscope, $\times 400$ ) show the HE staining images of the changes in the cochlear SV.

Fig. 2B Morphological structure of cochlear SV PCs under transmission electron microscopy 
The following are indicated in the figure: vascular basement membrane (BM) and pericytes (PCs). PCs were closely attached to the lateral wall of the BM. The shape of the PCs is shown by the arrow in the picture.

\section{mRNA content of TMEM16A, Bax, Bcl-2 and Caspase-3 in the cochlear SV}

The mRNA expression of TMEM16A, Bax, Bcl-2 and Caspase-3 was analyzed in cochlear SV from the different groups (Fig. 3). With the increase in age, the expression of TMEM16A mRNA in cochlear SV was increased $\left(n=3,{ }^{* \star *} P<0.001\right)$. The expression of TMEM16A mRNA in the $12 \mathrm{~m}$ OVX group was higher than that in the $12 \mathrm{~m}$ group $\left(\mathrm{n}=3,{ }^{\#} P<0.05\right)$. E2 intervention can downregulate the expression of TMEM16A mRNA in cochlear SV $(n=3$, \&\&\& $P<0.001)$. Then, the expression of apoptosis-related protein mRNA was detected. The expression of Caspase- 3 and Bax mRNA was increased in the cochlear SV of the 12 m group $\left(n=3,{ }^{*} P<0.05\right)$, and Bcl-2 mRNA was significantly decreased $\left(n=3,{ }^{* \star} P<0.001\right)$. The expressions of Caspase-3 and Bax mRNA in the $12 \mathrm{~m}$ OVX group were higher than those in the $12 \mathrm{~m}$ group ( $\left.\mathrm{n}=3,{ }^{\# \#} P<0.01,{ }^{\# \# \#} P<0.001\right)$, and Bcl-2 mRNA was significantly decreased $\left(\mathrm{n}=3,{ }^{\#} P<0.05\right)$. After the intervention of $E 2$, the expression of Caspase-3 and Bax mRNA decreased significantly $(\mathrm{n}=3$, \& $P$ $\left.<0.05,{ }^{\& \& \&} P<0.001\right)$, and Bcl-2 mRNA was significantly increased $(n=3,8 \& \&<0.001)$. The above results showed that with increasing age, the expression of apoptosis in cochlear SV was increased, while E2 can inhibit the apoptosis of cochlear SV. To further explore whether E2 can inhibit the apoptosis of cochlear SV PCs by regulating TMEM16A, we carried out experiments at the cellular level.

Fig. 3 mRNA content in the cochlear SV

A: The mRNA expression of TMEM16A in the cochlear SV between the different groups. B: The mRNA expression of Caspase-3 in cochlear SV. C: The mRNA expression of Bax in cochlear SV. D: The mRNA expression of Bcl-2 in cochlear SV. ${ }^{*} P<0.05,{ }^{* \star *} P<0.001$ vs. the 3 m group. ${ }^{\#} P<0.05,{ }^{\# \#} P<0.01,{ }^{\# \#} P<$ 0.001 vs. $12 \mathrm{~m}$ group. ${ }^{\&} P<0.05,{ }^{\& \& \&} P<0.001$ vs. $12 \mathrm{~m}$ OVX group.

\section{Primary culture and identification of PCs determined the cell aging model}

In the in vitro cell experiments, we performed primary culture of PCs and established an aging cell model. The studies revealed the growth state of PCs under an ordinary optical microscope (Fig. 4A). On the second day, the cochlear stria vascular tissue fragments were apparent. On the 7th day, the PCs had begun to grow out from the cochlear stria vascular tissue fragments and showed typical long spindle or few polygonal cells. The cells proliferated rapidly throughout the culture dish by day 12 , reaching $90 \%$ density and passaging. Primary cultured PCs were observed using a fluorescence inverted microscope $(\times 400$, Fig. 4B). In the primary culture of PCs, the expression of Desmin and a-SM-actin was positive (green), and there was no observed expression of vWF (a specific marker of endothelial cells). Thus, we generated pure primary cultures of PCs. PCs were stained with $\beta$-galactosidase after continuous passage (Fig. 4C). In the P13 group, the cultured cells were obviously aged, and the number of positive cells was 
significantly higher than that in the P5 group $\left(n=3,{ }^{* \star *} P<0.001\right)$. Therefore, we selected the P13 PCs as the aging cell group.

Fig. 4. Primary culture of PCs and analysis of the cell aging group

A: Primary culture of PC growth processes under an inverted microscope $(\times 200)$. B: Identification of primary cultured PCs. Fluorescence inverted microscope $(\times 400)$. The expression of desmin and a-SMactin was positive (green). The EC-specific marker vWF was negative. C: $\beta$-galactosidase staining of PCs. Figs. a1, b1 and c1 show 10x microscopy observations. Figs. a2, b2 and c2 show 40x microscopy observations. D: Counting of positive cells stained with $\beta$-galactosidase. ${ }^{\star} P<0.05,{ }^{\star \star \star} P<0.001$ vs. the P5 group.

\section{Immunofluorescence detection of TMEM16A expression}

We used immunofluorescence to observe the expression of TMEM16A in different groups of PCs (Fig. 5). Compared with the P5 group, the results showed that the expression of TMEM16A was increased in the $\mathrm{P} 13$ group $\left(\mathrm{n}=6,{ }^{* \star} P<0.01\right)$. When the P13 PCs were treated with E2, the expression of TMEM16A was decreased $\left(n=6,{ }^{\#} P<0.01\right)$. These results indicated that E2 could reduce the expression of TMEM16A in the aging $P C$ group.

Fig. 5 Expression of TMEM16A in primary cultured PCs

Fluorescence inverted microscope $(\times 400)$ A: TMEM16A is labeled with green fluorescence, and DAPI staining labeled the nucleus. B: Expression changes of TMEM16A in PCs. ${ }^{*} P<0.01$ vs. the P5 group. ${ }^{\# \#} P$ $<0.01$ vs. the $\mathrm{P} 13$ group.

\section{Apoptosis was detected by flow cytometry}

To further determine whether E2 has an effect on PC apoptosis through TMEM16A, we detected the apoptosis rate by flow cytometry (Fig. 6). Compared with the P5 group, the apoptosis rate in the P13 group was significantly increased $\left(n=3,{ }^{* \star *} P<0.001\right)$. When the P13 PCs were treated with E2 or T16Ainh$\mathrm{A} 01$, the apoptosis rate was decreased $\left(\mathrm{n}=3,{ }^{\# \#} P<0.01\right.$, and $\left.{ }^{\# \# \#} P<0.001\right)$, and after intervention with both T16Ainh-A01 and E2, the rate was significantly decreased ( $\left.n=3,{ }^{\# \#} P<0.001\right)$. According to the results of this experiment and previous immunofluorescence results, it was found that E2 could inhibit the apoptosis of PCs through downregulating the expression of TMEM16A.

Fig. 6 The apoptosis rate of PCs

A: Apoptosis was detected by flow cytometry. B: Apoptosis rates. ${ }^{* \star} P<0.001$ vs. the $P 5$ group. ${ }^{\# \#} P<0.01$ and ${ }^{\# \#} P<0.001$ vs. $P 13$ group.

\section{Discussion}


Presbycusis is the most common sensory disorder in the elderly, and approximately $1 / 3$ of people over the age of 65 suffer from presbycusis(Homans et al. 2017). There is currently still a lack of effective prevention and treatment measures for presbycusis. In our study, we further explored the possible mechanism of E2 in protecting against presbycusis. The results showed that E2 can inhibit apoptosis of PCs in the cochlear SV through downregulating the expression of TMEM16A, thus improving the hearing loss of aged C57BL/6J mice.

Presbycusis is a type of sensorineural hearing loss caused by the degeneration of the inner ear structure and bilateral symmetry. The etiology of presbycusis is complex and has not been clearly studied(Frisina 2009;Ohlemiller et al. 2010). At present, it is believed that one of the fundamental causes of strial presbycusis is the dysfunction caused by the degeneration of SV(Spicer and Schulte 2005). Early studies have reported cochlear SV contraction in gerbils, and the contraction rate increases with age(Gratton and Schulte 1995). When the atrophy of the cochlear SV reaches a certain extent, the capillaries and PCs are reduced or lost(Ocho et al. 2000), the PC cell structure is abnormal, the cytoplasm and chromatin are lost, and the cell vacuoles are increased(Neng et al. 2015). Our results showed that in the $12 \mathrm{~m}$ group, the ABR threshold was increased, which was consistent with the process of presbycusis. The cochlear SV of 12month-old mice showed a large degree of vacuolar degeneration, loss of chromatin organelles and cytoplasmic swelling in PCs. It was verified that with increasing age, the morphological structure changes of cochlear SV PCs may lead to age-related hearing loss. Some studies have shown that estrogen (E2) has a protective effect on hearing(Hederstierna et al. 2007). The ABR threshold of the auditory brainstem response in postmenopausal women is significantly higher than that in young women and men(Jerger and Johnson 1988; Wharton and Church 1990), suggesting that this difference may be related to the level of E2. Animal experiments have shown that the hearing threshold in ovariectomized rats is significantly higher than that in normal rats(Coleman et al. 1994). In our experiment, we found that after mice were ovariectomized, the ABR threshold was significantly increased, the cochlear SV was obviously atrophic, and the PC degeneration was more obvious. In addition, after the intervention of E2, the ABR threshold was decreased and the cochlear SV and PC degeneration were improved. Thus, our data demonstrated that E2 may reduce hearing loss in presbycusis by improving cochlear SV atrophy and the morphological structure of PCs in aging mice.

Some studies have reported that E2 has the effect of anti-apoptosis, and it has been proven that estrogen can protect the heart by inhibiting the apoptosis of human umbilical vein endothelial cells induced by endoplasmic reticulum stress (ERS) as an anti-apoptotic agent(Su et al. 2017). E2 can also reduce the apoptosis of cochlear outer hair cells against gentamicin ototoxicity through inhibition of the JNK pathway(Nakamagoe et al. 2010). As many studies on presbycusis have found that it can cause cochlear cell degeneration, autophagy and apoptosis were increased(Huang et al. 2017;Sanchez-Rodriguez et al. 2018; Yuan et al. 2018). Based on the protective effect of E2 on cochlear apoptosis, our animal experiments showed that the apoptosis of cochlear SV increased in ovariectomized mice, and E2 intervention decreased the apoptosis. In the cell experiment, it was further found that the apoptosis rate of PCs increased significantly in the aging group and decreased significantly after the intervention of E2. 
TMEM16A is an important constituent protein of CaCCs(Forge and Wright 2002). In the study of hearing and TMEM16A, it was found that TMEM16A was expressed in cochlear spiral ganglion cells(Zhang et al. 2015), cochlear SV basal cells(Jeon et al. 2011) and cochlear inner supporting cells(Wang et al. 2015). Early studies in our laboratory showed that there were also age-related TMEM16A changes in the PCs of guinea pig cochlear SV(Zhou et al. 2019). In our study, the expression of TMEM16A mRNA in the cochlear SV of aging C57BL/6J mice was increased. Cell-level studies have shown that TMEM16A was also expressed in primary cultured PCs and that its expression increased in the aging cell group, which was in accordance with the animal experiment. The above results showed that the change in TMEM16A expression was related to presbycusis. The expression and function of TMEM16A vary with cell type. Some studies have shown that TMEM16A is closely related to the apoptosis of cancer(Wilkerson and Reis-Filho 2013), suggesting that TMEM16A may be a potential biomarker of some aggressive diseases(Deng et al. 2016;Song et al. 2018;Frobom et al. 2019). For normal cells of the body, such as podocytes(Lian et al. 2017) and smooth muscle cells(Zeng et al. 2018;Zeng et al. 2019), overexpression of TMEM16A can promote apoptosis of these cells and further lead to the occurrence of disease. However, it has not been reported whether TMEM16A can affect presbycusis by regulating cochlear cell apoptosis. Further experiments showed that the expression of TMEM16A and apoptosis increased in the aging PC group. After treatment with T16Ainh-A01, the apoptosis rate of PCs in the aging group decreased significantly. These results suggest that TMEM16A is related to the apoptosis of PCs of cochlear SV and that inhibition of TMEM16A expression can reduce the apoptosis of PCs. In addition, we also found that the expression of TMEM16A decreased significantly when the ovariectomized mice were treated with E2. At the cellular level, we found that the expression of TMEM16A in the PCs of the aging group decreased after E2 intervention. Combined with the previous effect of E2 on PC apoptosis, it is suggested that E2 may inhibit the apoptosis of PCs in the aging cochlear SV through downregulating the expression of TMEM16A.

However, this study reveals that E2 may only partially affect presbycusis by regulating the effect of TMEM16A on apoptosis. Understanding how E2 specifically regulates the expression or function of TMEM16A and the associated molecular mechanism are the issues that need to be addressed in the future. Nevertheless, the present findings provide a clearer understanding of the effects of E2 on the internal microcirculation and auditory function of the cochlea, and they provide a theoretical basis for the use of E2 as a potential drug in the prevention and treatment of presbycusis.

\section{Conclusions}

In summary, due to the increased expression of TMEM16A, which can lead to an increase in the apoptosis of PCs, estrogen can downregulate the expression of TMEM16A and can also reduce the apoptosis of PCs. These data suggest that estrogen may reduce apoptosis in PCs by downregulating the expression of TMEM16A, which provides a protective effect on presbycusis.

\section{Abbreviations}




\begin{tabular}{|ll|}
\hline ABR & Auditory brainstem response \\
\hline BM & Basement membrane \\
\hline CaCCs & Calcium-activated chloride channels \\
\hline DAPI & 4',6-diamidino-2-phenylindole \\
\hline E2 & Estrogen \\
\hline HE & Hematoxylin and eosin \\
PBS & Phosphate buffer saline \\
\hline PCs & Pericytes \\
\hline SV & Stria vascularis \\
\hline TMEM16A & Transmembrane member 16A \\
\hline
\end{tabular}

\section{Declarations}

\section{Ethics approval and consent to participate}

The use of animals in the present study was approved by the Committee of Animal Experimental Ethics of The First Affiliated Hospital of Medical College, Shihezi University (permit no. A2018-160-01).

\section{Consent for publication}

Not applicable.

\section{Availability of data and materials}

The analysed data sets generated during the study are available from the corresponding author on reasonable request.

\section{Competing interests}

The authors declare that they have no competing interests.

\section{Funding}

This work was supported by National Nature Science Foundation of China (No. 81560175; 81960188)

\section{Authors' contributions}

$\mathrm{LL}, \mathrm{KM}$ and $\mathrm{JS}$ designed the experiments. $\mathrm{XL}, \mathrm{YZ}, \mathrm{LC}$ and $\mathrm{ZF}$ conducted the experiments. $\mathrm{XL}, \mathrm{YZ}, \mathrm{LC}$ and $Z F$ acquired the data. $X L, Y Z, K M, L L$ and JQS analyzed the data. $X L$ and $L L$ wrote the manuscript. All authors read and approved the final manuscript. 
Acknowledgements

Not applicable

\section{Publisher's Note}

Xuerui Li and Yang zhang contributed equally to this work.

Author》

1.Xuerui Li Email: lixuerui020@163.com

2.Yang Zhang Email: yimisunshine2017@163.com

3.Long Chen Email: 121735804@qq.com

4.Ziyi Feng Email:572840499@qq.com

5.Ketao Ma Email: maketao@hotmail.com

6.Jun-Qiang Si Email: sijunqiang@shzu.edu.cn

Corresponding author:Professor Li Li or Professor Jun-Qiang Si

E-mail addresses: Lily7588@163.com (Li Li), sijunqiang@shzu.edu.cn (Jun-Qiang Si)

Adresses: Department of Physiology, Medical College of Jiaxing University, No.118 Jiahang Road, Jiaxing, Zhejiang 341000, PR China.

\section{References}

Allawzi AM, Vang A, Clements RT, Jhun BS, Kue NR, Mancini TJ, et al. Activation of Anoctamin-1 Limits Pulmonary Endothelial Cell Proliferation via p38-Mitogen-activated Protein Kinase-Dependent Apoptosis. Am J Respir Cell Mol Biol. 2018;58(5):658-67. doi:10.1165/rcmb.2016-03440C.

Betto G, Cherian O, Pifferi S, Cenedese V, Boccaccio A, Menini A. Interactions between permeation and gating in the TMEM16B/anoctamin2 calcium-activated chloride channel. The Journal of general physiology. 2014;143(6):703-18. doi:10.1085/jgp.201411182.

Bielefeld EC, Tanaka C, Chen GD, Henderson D. Age-related hearing loss: is it a preventable condition? Hear Res. 2010;264(1-2):98-107. doi:10.1016/j.heares.2009.09.001.

Ciorba A, Hatzopoulos S, Bianchini C, Aimoni C, Skarzynski H, Skarzynski PH. Genetics of presbycusis and presbystasis. Int J Immunopathol Pharmacol. 2015;28(1):29-35. doi:10.1177/0394632015570819. Coleman JR, Campbell D, Cooper WA, Welsh MG, Moyer J. Auditory brainstem responses after ovariectomy and estrogen replacement in rat. Hear Res. 1994;80(2):209-15. doi:10.1016/0378- 
5955(94)90112-0.

Davis A, Wood S, Healy R, Webb H, Rowe S. Risk factors for hearing disorders: epidemiologic evidence of change over time in the UK. J AM ACAD AUDIOL. 1995;6(5):365-70. doi.

Deng L, Yang J, Chen H, Ma B, Pan K, Su C, et al. Knockdown of TMEM16A suppressed MAPK and inhibited cell proliferation and migration in hepatocellular carcinoma. Onco Targets Ther. 2016;9:325-33. doi:10.2147/OTT.S95985.

Forge A, Wright T. The molecular architecture of the inner ear. Br Med Bull. 2002;63:5-24. doi:10.1093/bmb/63.1.5.

Frobom R, Sellberg F, Xu C, Zhao A, Larsson C, Lui WO, et al. Biochemical Inhibition of D0G1/TMEM16A Achieves Antitumoral Effects in Human Gastrointestinal Stromal Tumor Cells In Vitro. ANTICANCER RES. 2019;39(7):3433-42. doi:10.21873/anticanres.13489.

Gratton MA, Schmiedt RA, Schulte BA.Age-related decreases in endocochlear potential are associated with vascular abnormalities in the stria vascularis. Hear Res. 1996;102 (1-2): 181 - 90. doi:

10.1016/s0378-5955(96)90017-9.

Gratton MA, Schulte B. A.Alterations in microvasculature are associated with atrophy of the stria vascularis in quiet-aged gerbils. Hear Res. 1995;82(1):44-52. doi:10.1016/0378-5955(94)00161-i. Hederstierna C, Hultcrantz M, Collins A, Rosenhall U. Hearing in women at menopause. Prevalence of hearing loss, audiometric configuration and relation to hormone replacement therapy. Acta Otolaryngol. 2007;127(2):149-55. doi:10.1080/00016480600794446.

Helzner EP, Cauley JA, Pratt SR, Wisniewski SR, Zmuda JM, Talbott EO, et al. Race and sex differences in age-related hearing loss: the Health, Aging and Body Composition Study. J AM GERIATR SOC. 2005;53(12):2119-27. doi:10.1111/j.1532-5415.2005.00525.x.

Huang Q, Zheng Y, Ou Y, Xiong H, Yang H, Zhang Z, et al. miR-34a/Bcl-2 signaling pathway contributes to age-related hearing loss by modulating hair cell apoptosis. NEUROSCI LETT. 2017;661:51-6.

doi:10.1016/j.neulet.2017.07.044.

Jafari Z, Kolb BE, Mohajerani MH. .Age-related hearing loss and tinnitus, dementia risk, and auditory amplification outcomes. AGEING RES REV. 2019;56:100963. doi:10.1016/j.arr.2019.100963.

Jeon JH, Park JW, Lee JW, Jeong SW, Yeo SW, Kim IB. .Expression and immunohistochemical localization of TMEM16A/anoctamin 1, a calcium-activated chloride channel in the mouse cochlea. CELL TISSUE RES. 2011;345(2):223-30. doi:10.1007/s00441-011-1206-6.

Jerger J, Johnson K.Interactions of age, gender, and sensorineural hearing loss on ABR latency. Ear Hear. 1988;9 (4): 168 - 76. doi: 10.1097/00003446-198808000-00002.

Lian $\mathrm{H}$, Cheng Y, Wu X. TMEM16A exacerbates renal injury by activating P38/JNK signaling pathway to promote podocyte apoptosis in diabetic nephropathy mice. Biochem Biophys Res Commun. 2017;487(2):201-8. doi:10.1016/j.bbrc.2017.04.021.

Ling S, Dai A, Dilley RJ, Jones M, Simpson E, Komesaroff PA, et al. Endogenous estrogen deficiency reduces proliferation and enhances apoptosis-related death in vascular smooth muscle cells: insights from the aromatase-knockout mouse. CIRCULATION. 2004;109(4):537-43.

doi:10.1161/01.CIR.0000109699.45186.30. 
Menardo J, Tang Y, Ladrech S, Lenoir M, Casas F, Michel C, et al. Oxidative stress, inflammation, and autophagic stress as the key mechanisms of premature age-related hearing loss in SAMP8 mouse Cochlea. Antioxid Redox Signal. 2012;16(3):263-74. doi:10.1089/ars.2011.4037.

Nakamagoe M, Tabuchi K, Uemaetomari I, Nishimura B, Hara A. Estradiol protects the cochlea against gentamicin ototoxicity through inhibition of the JNK pathway. Hear Res. 2010;261(1-2):67-74.

doi:10.1016/j.heares.2010.01.004.

Neng L, Zhang J, Yang J, Zhang F, Lopez IA, Dong M, et al. Structural changes in thestrial blood-labyrinth barrier of aged C57BL/6 mice. CELL TISSUE RES. 2015;361(3):685-96. doi:10.1007/s00441-015-2147-2. Ocho S, Iwasaki S, Umemura K. Hoshino T.A new model for investigating hair cell degeneration in the guinea pig following damage of the stria vascularis using a photochemical reaction. Eur Arch Otorhinolaryngol. 2000;257(4):182-7. doi:10.1007/s004050050219.

Sanchez-Rodriguez C, Cuadrado E, Riestra-Ayora J, Sanz-Fernandez R. Polyphenols protect against ageassociated apoptosis in female rat cochleae. BIOGERONTOLOGY. 2018;19(2):159-69.

doi:10.1007/s10522-018-9747-7.

Shi X. Cochlear pericyte responses to acoustic trauma and the involvement of hypoxia-inducible factor1alpha and vascular endothelial growth factor. AM J PATHOL. 2009;174(5):1692-704.

doi:10.2353/ajpath.2009.080739.

Shi X, Han W, Yamamoto H, Tang W, Lin X, Xiu R, et al. The cochlear pericytes. MICROCIRCULATION. 2008;15(6):515-29. doi:10.1080/10739680802047445.

Song Y, Gao J, Guan L, Chen X, Gao J, Wang K. Inhibition of AN01/TMEM16A induces apoptosis in human prostate carcinoma cells by activating TNF-alpha signaling. CELL DEATH DIS. 2018;9(6):703. doi:10.1038/s41419-018-0735-2.

Spicer SS, Schulte BA.Pathologic changes of presbycusis begin in secondary processes and spread to primary processes of strial marginal cells. Hear Res. 2005;205 (1-2): 225 - 40. doi:

10.1016/j.heares.2005.03.022.

Wang HC, Lin CC, Cheung R, Zhang-Hooks Y, Agarwal A, Ellis-Davies G, et al. Spontaneous Activity of Cochlear Hair Cells Triggered by Fluid Secretion Mechanism in Adjacent Support Cells. CELL. 2015;163(6):1348-59. doi:10.1016/j.cell.2015.10.070.

Wharton JA, Church GT. .Influence of menopause on the auditory brainstem response. Audiology. 1990;29(4):196-201. doi:10.3109/00206099009072850.

Wilkerson PM, Reis-Filho JS. .The 11q13-q14 amplicon: clinicopathological correlations and potential drivers. Genes Chromosomes Cancer. 2013;52(4):333-55. doi:10.1002/gcc.22037.

Williamson TT, Zhu X, Pineros J, Ding B, Frisina R. D.Understanding hormone and hormone therapies' impact on the auditory system. J NEUROSCI RES. 2020. doi:10.1002/jnr.24588.

Wu SY, Chen YW, Tsai SF, Wu SN, Shih YH, Jiang-Shieh YF, et al. Estrogen ameliorates microglial activation by inhibiting the Kir2.1 inward-rectifier K(+) channel. Sci Rep. 2016;6:22864.

doi:10.1038/srep22864.

Yang $\mathrm{H}$, Xiong $\mathrm{H}$, Huang Q, Pang J, Zheng X, Chen L, et al. Compromised potassium recycling in the cochlea contributes to conservation of endocochlear potential in a mouse model of age-related hearing loss. NEUROSCI LETT. 2013;555:97-101. doi:10.1016/j.neulet.2013.09.028. 
Yuan J, Zhao X, Hu Y, Sun H, Gong G, Huang X, et al. Autophagy regulates the degeneration of the auditory cortex through the AMPK-mTOR-ULK1 signaling pathway. INT J MOL MED. 2018;41(4):2086-98. doi:10.3892/ijmm.2018.3393.

Zeng JW, Chen BY, Lv XF, Sun L, Zeng XL, Zheng HQ, et al. Transmembrane member $16 \mathrm{~A}$ participates in hydrogen peroxide-induced apoptosis by facilitating mitochondria-dependent pathway in vascular smooth muscle cells. Br J Pharmacol. 2018;175(18):3669-84. doi:10.1111/bph.14432.

Zeng JW, Chen BY, Lv XF, Sun L, Zeng XL, Zheng HQ, et al. Transmembrane member $16 \mathrm{~A}$ participates in hydrogen peroxide-induced apoptosis by facilitating mitochondria-dependent pathway in vascular smooth muscle cells. Br J Pharmacol. 2018;175(18):3669-84. doi:10.1111/bph.14432.

Zeng XL, Sun L, Zheng HQ, Wang GL, Du YH, Lv XF, et al. Smooth muscle-specific TMEM16A expression protects against angiotensin II-induced cerebrovascular remodeling via suppressing extracellular matrix deposition. J MOL CELL CARDIOL. 2019;134:131-43. doi:10.1016/j.yjmcc.2019.07.002.

Zhang J, Chen S, Cai J, Hou Z, Wang X, Kachelmeier A, et al. Culture media-based selection of endothelial cells, pericytes, and perivascular-resident macrophage-like melanocytes from the young mouse vestibular system. Hear Res. 2017;345:10-22. doi:10.1016/j.heares.2016.12.012.

Zhang XD, Lee JH, Lv P, Chen WC, Kim HJ, Wei D, et al.Etiology of distinct membrane excitability in preand posthearing auditory neurons relies on activity of Cl-channel TMEM16A 2015.

Zhou Y, Song J, Wang YP, Zhang AM, Tan CY, Liu YH, et al. Ageassociated variation in the expression and function of TMEM16A calciumactivated chloride channels in the cochlear stria vascularis of guinea pigs. MOL MED REP. 2019;20(2):1593-604. doi:10.3892/mmr.2019.10423.

\section{Figures}




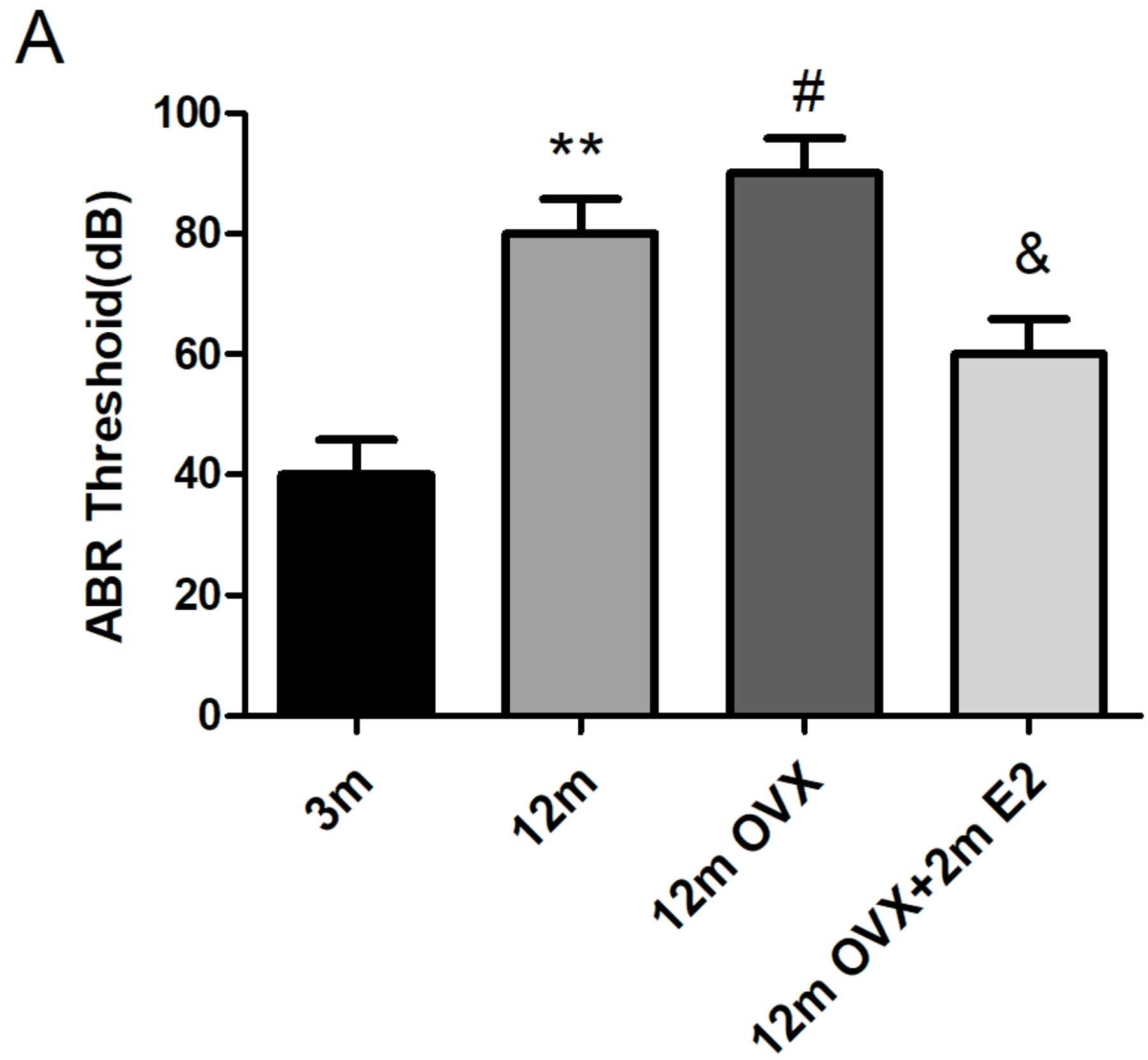

Figure 1

ABR threshold results of each group The results are presented as the mean $\pm S D, n=10$. ${ }^{\star \star} P<0.01$ vs. the $3 \mathrm{~m}$ group. $\# \mathrm{P}<0.05$ vs. $12 \mathrm{~m}$ group. $\& \mathrm{P}<0.05$ vs. the $12 \mathrm{~m}$ OVX group. 
A
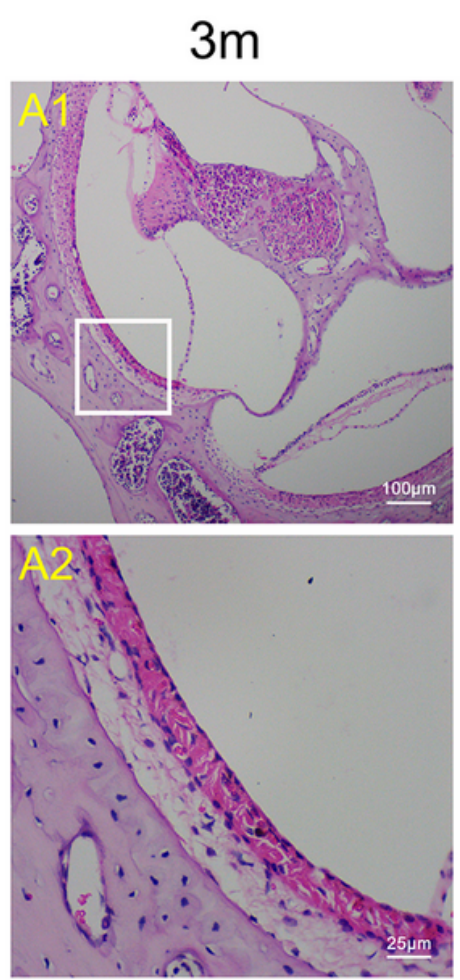

B

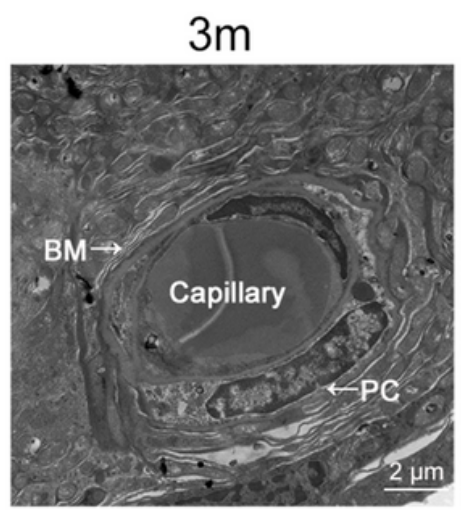

$12 \mathrm{~m}$
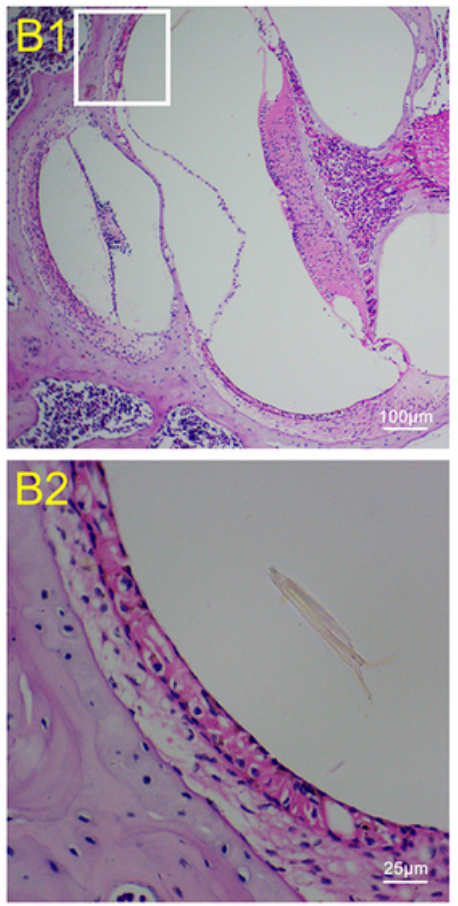

$12 m$

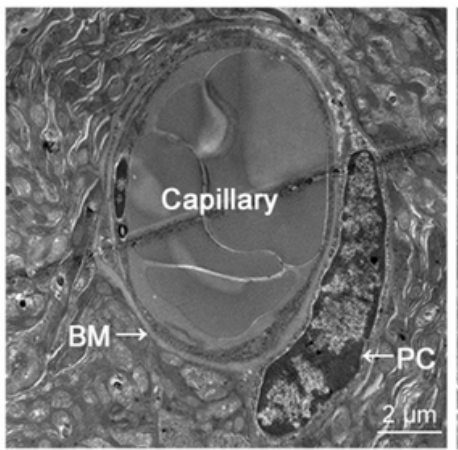

$12 \mathrm{~m}$ OVX
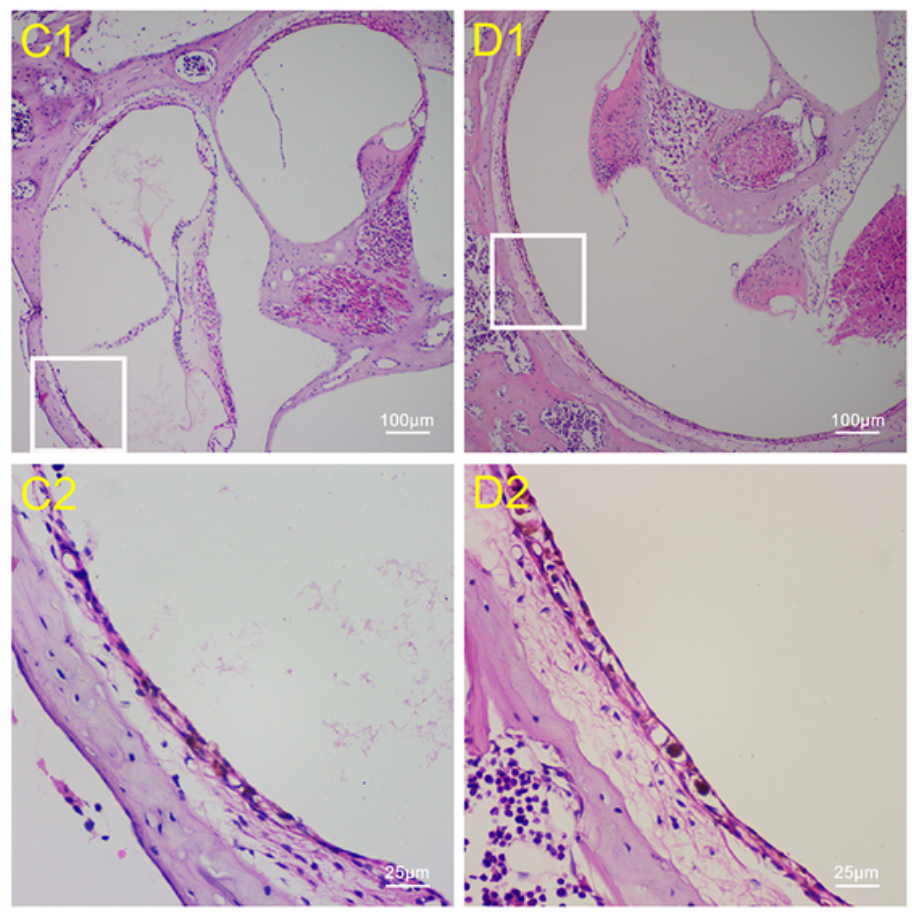

$12 \mathrm{~m}$ OVX

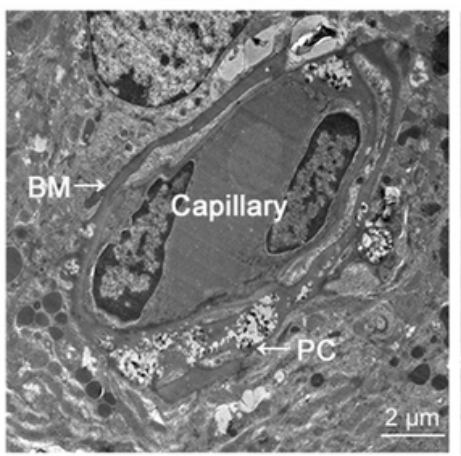

$12 m$ OVX $+2 m$ E2

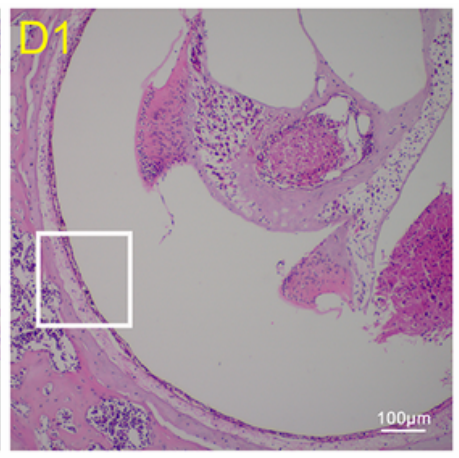

$12 m$ OVX+2m E2

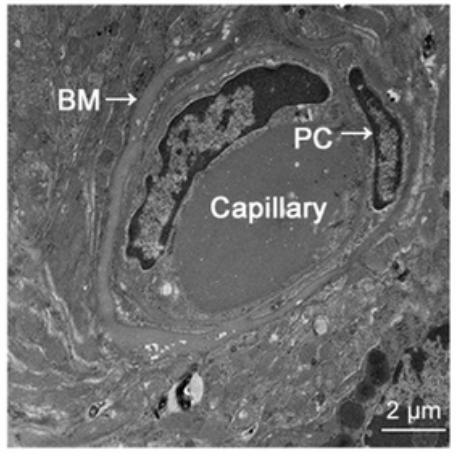

\section{Figure 2}

Fig. 2A HE staining of the cochlear SV in each group Fig. 2A1 to D1 inverted microscope $(\times 100)$ and Fig. $3 A 2$ to $D 2$ inverted microscope $(\times 400)$ show the HE staining images of the changes in the cochlear SV. Fig. 2B Morphological structure of cochlear SV PCs under transmission electron microscopy The following are indicated in the figure: Vascular basement membrane (BM) and pericytes (PCs). PCs were closely attached to the lateral wall of the BM. The shape of the PCs is shown by the arrow in the picture. 
A

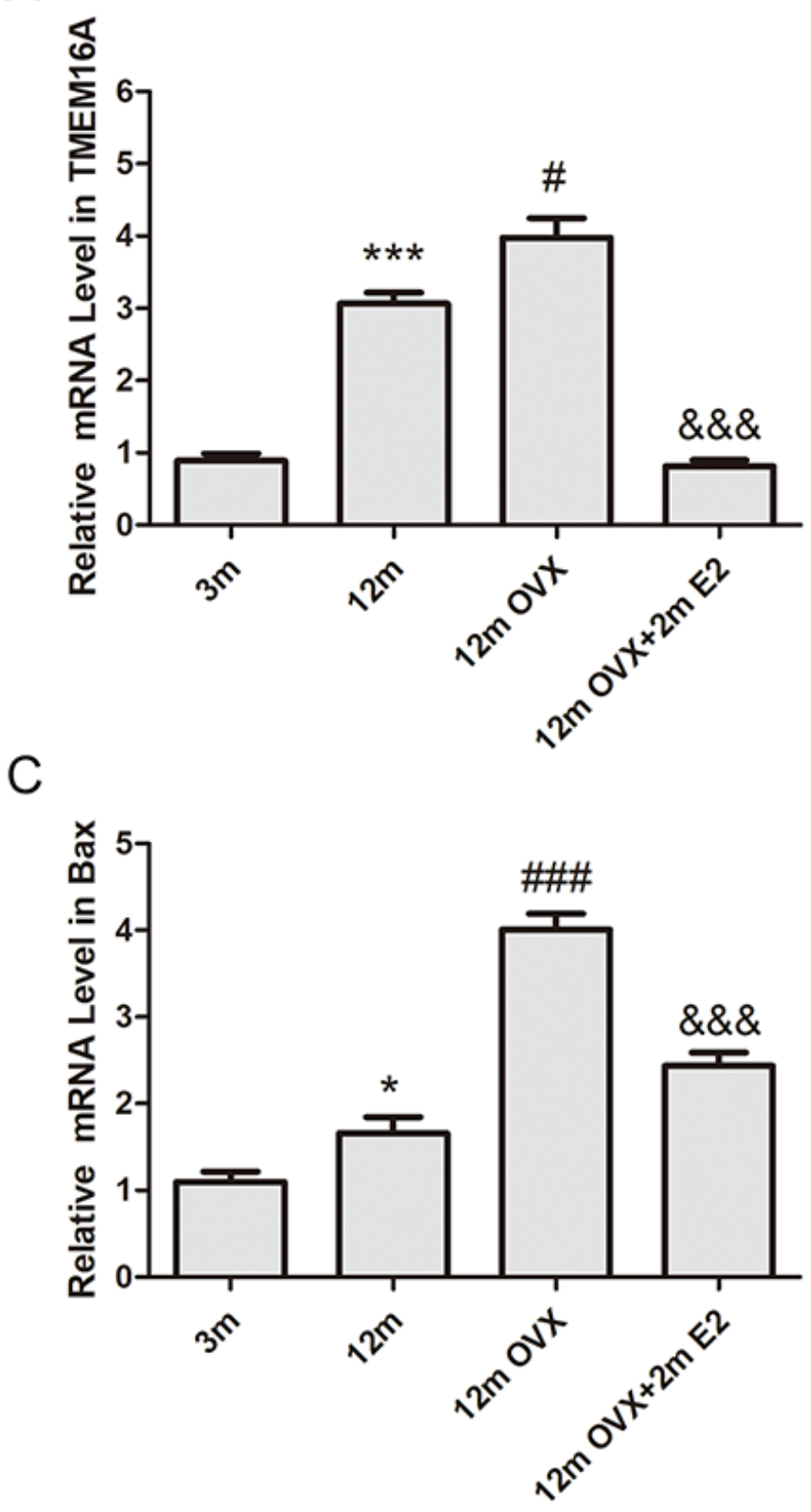

B

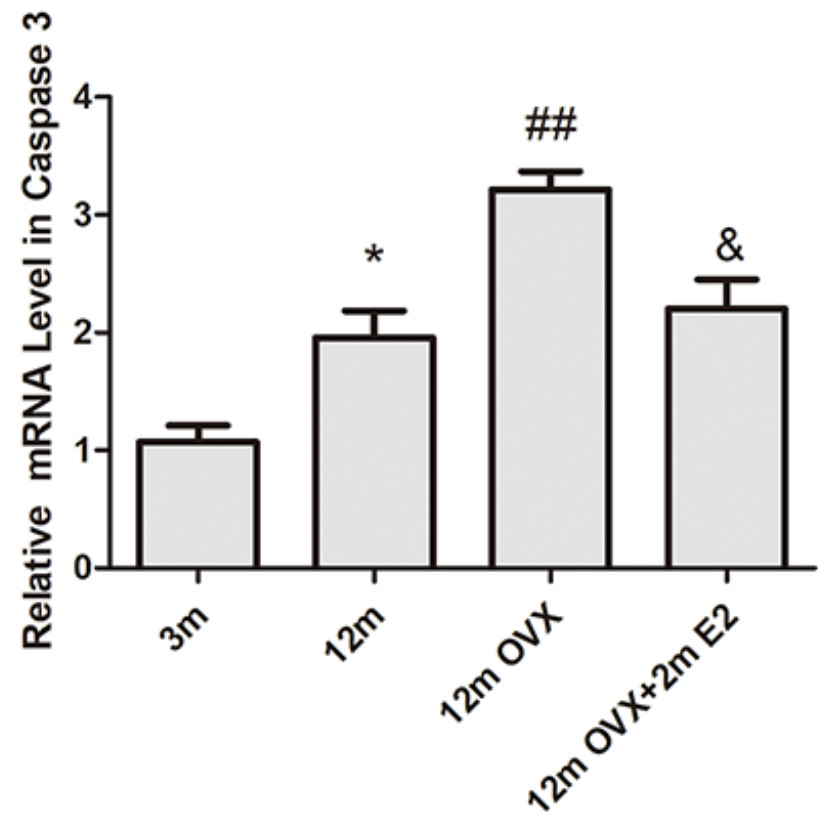

D

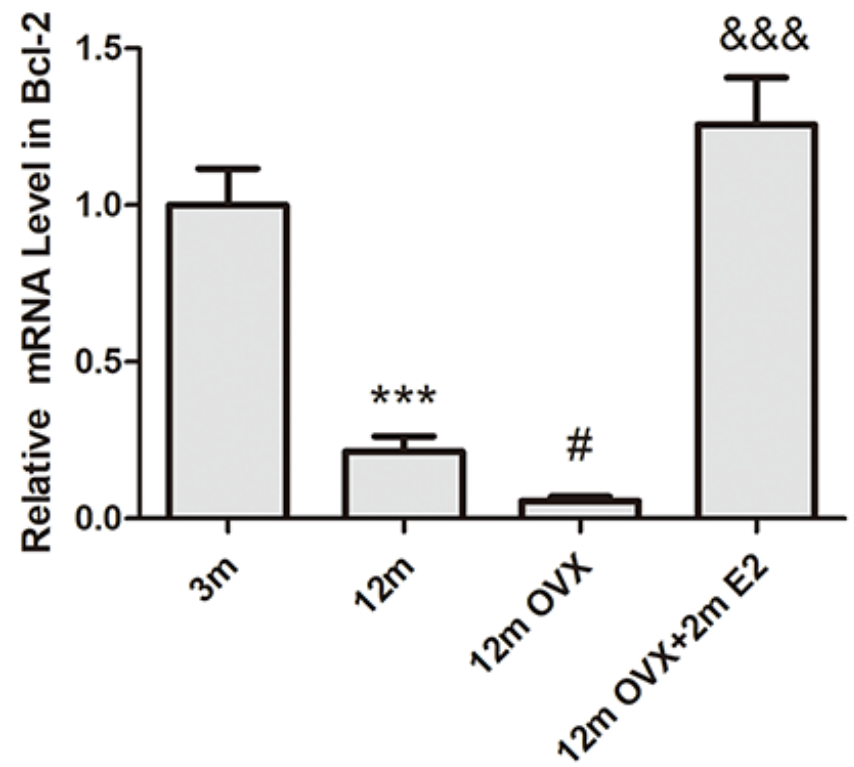

Figure 3

mRNA content in the cochlear SV A: The mRNA expression of TMEM16A in the cochlear SV cells between the different groups. B: The mRNA expression of Caspase-3 in cochlear SV cells. C: The mRNA expression of Bax in cochlear SV cells. D: The mRNA expression of Bcl-2 in cochlear SV cells. ${ }^{\star} \mathrm{P}<0.05,{ }^{\star * \star} \mathrm{P}<0.001$ vs. the $3 \mathrm{~m}$ group. $\# \mathrm{P}<0.05, \# \# \mathrm{P}<0.01, \# \# \# \mathrm{P}<0.001$ vs. $12 \mathrm{~m}$ group. $\& \mathrm{P}<0.05, \& \& \& \mathrm{P}<0.001 \mathrm{vs} .12 \mathrm{~m}$ OVX group. 
A

Day 2

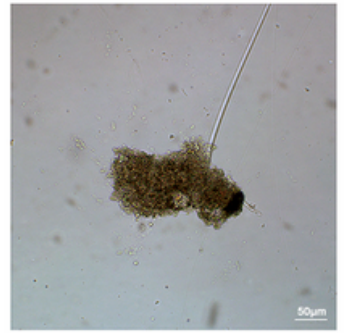

B
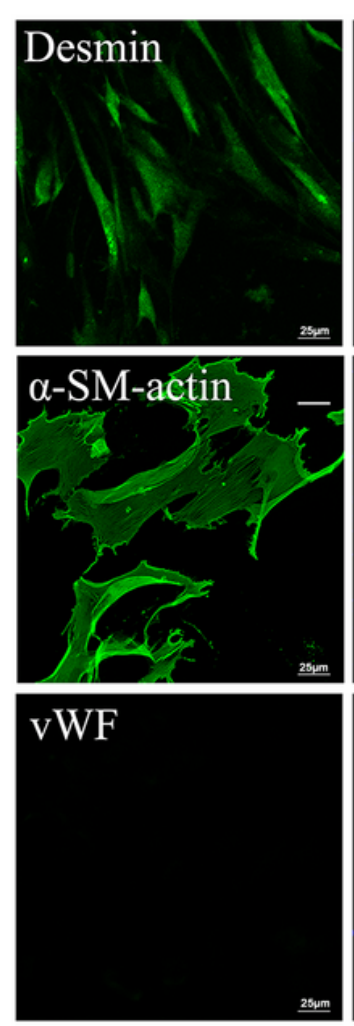
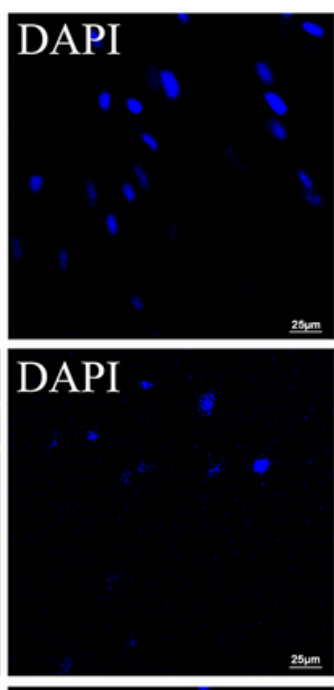

Day 7
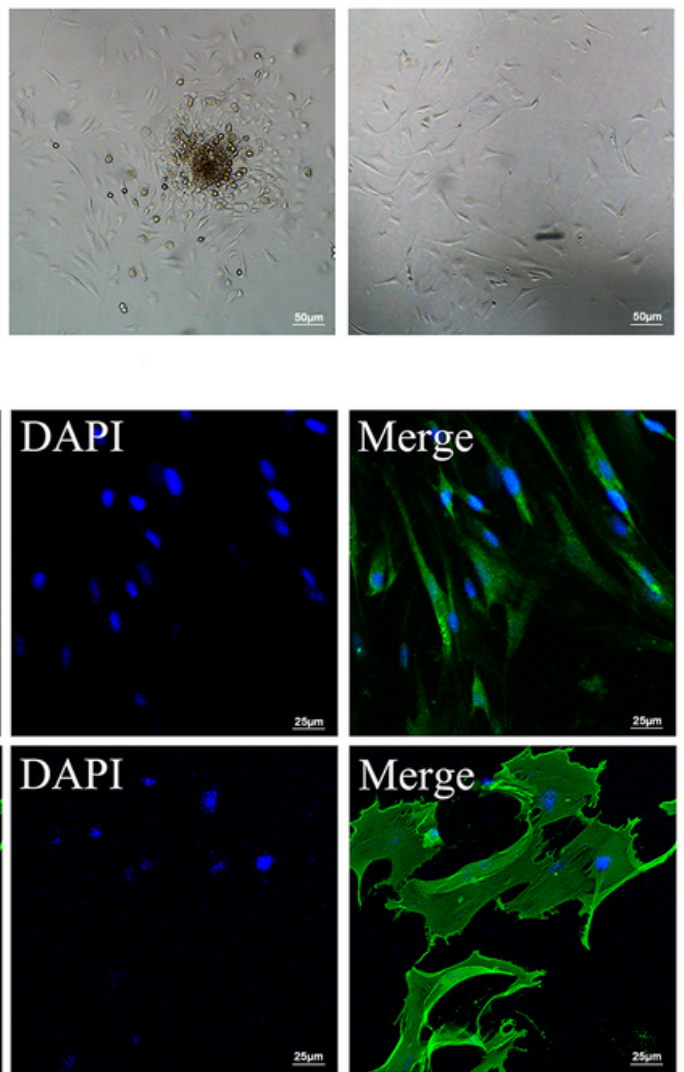

DAPI

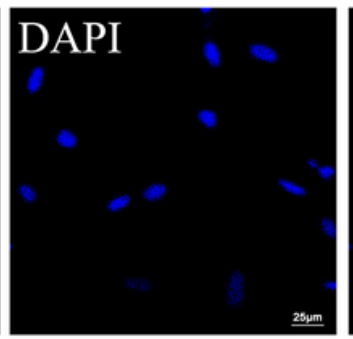

Day 12

Merge
C

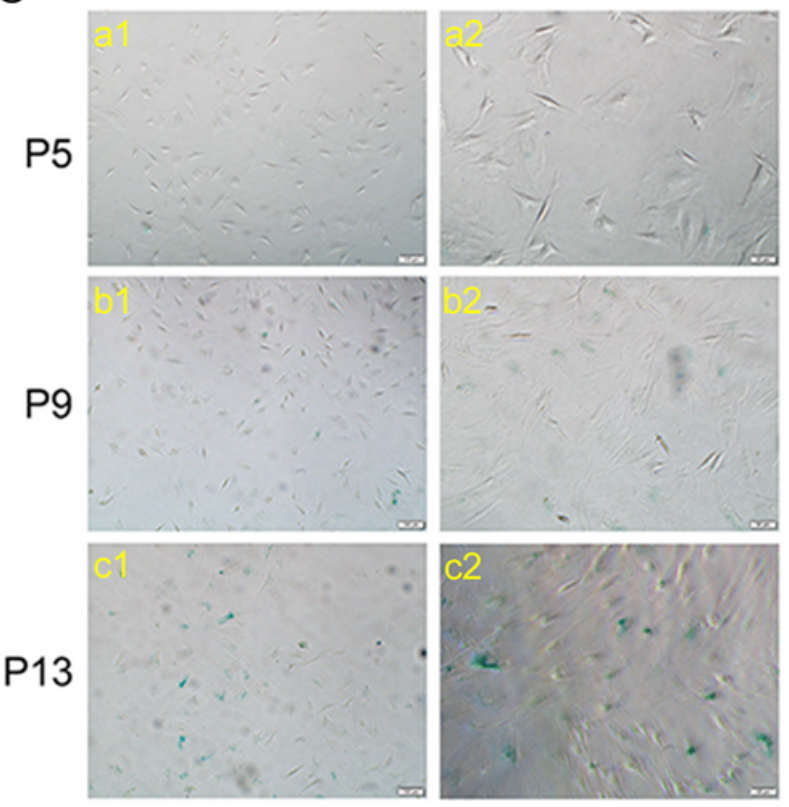

D

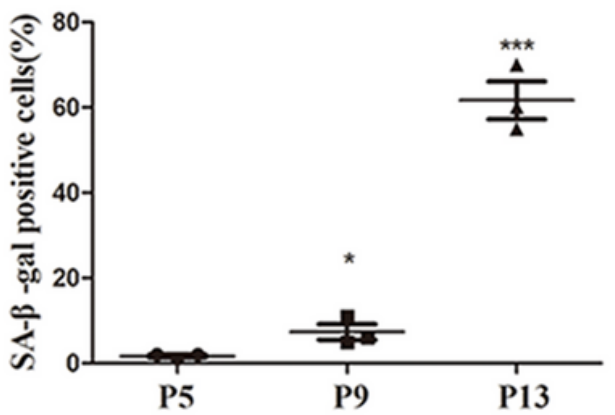

\section{Figure 4}

Primary culture of PCs and analysis of the cell aging group A: Primary culture of PCs growth processes under an inverted microscope (×200). B: Identification of primary cultured PCs. Fluorescence inverted microscope $(\times 400)$. The expression of Desmin and a-SM-actin was positive (green). The EC-specific marker vWF was negative. C: $\beta$-galactosidase staining of PCs. In Figs. a1, b1 and c1 are 10x microscope observations. In Figs. a2, b2 and c2 are 40x microscope observations. D: Counting of positive cells stained with $\beta$-galactosidase. ${ }^{*} P<0.05$, ${ }^{\star *} P<<0.001$ vs. the $P 5$ group. 


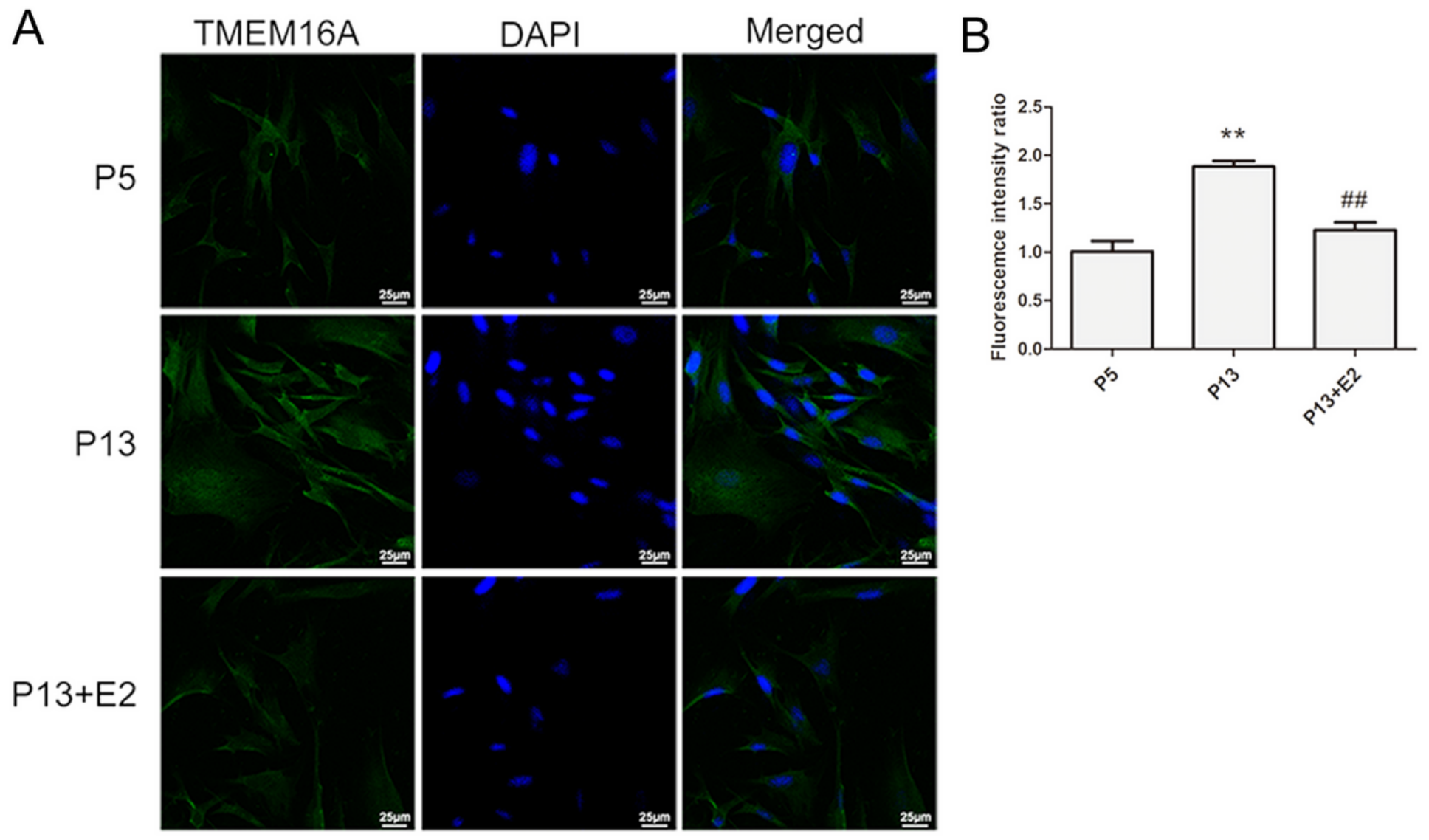

Figure 5

Expression of TMEM16A in primary cultured PCs Fluorescence inverted microscope $(\times 400) \mathrm{A}$ : TMEM16A is labeled with green fluorescence, and DAPI staining labeled the nucleus. B: Expression changes of TMEM16A in PCs. **P $<0.01$ vs. the P5 group. \#\#P<0.01 vs. P13 group.

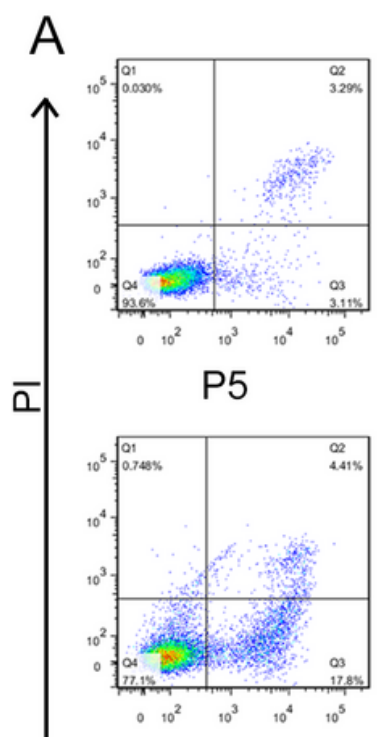

E2
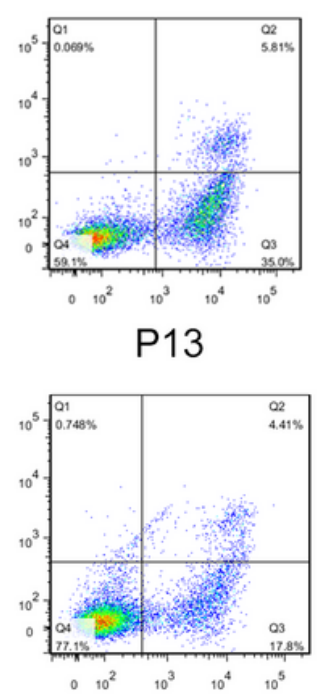

T16Ainh-A01
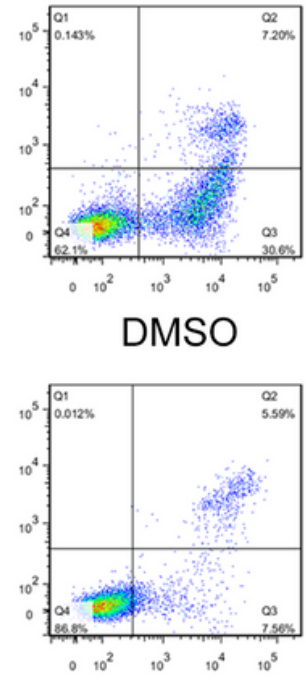

T16Ainh-A01+E2
$\mathrm{B}$

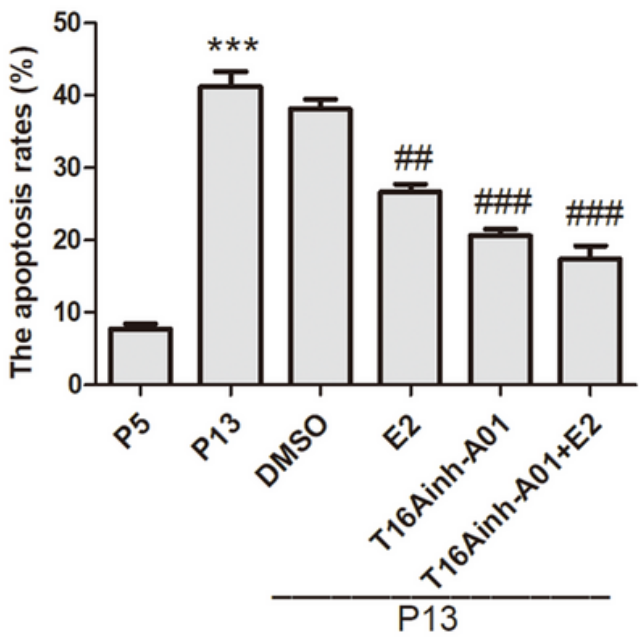

Annexin V-FITC

Figure 6 
The apoptosis rate of PCs A: Apoptosis was detected by flow cytometry. B: Apoptosis rates. ${ }^{\star * *} \mathrm{P}<0.001$ vs. the $\mathrm{P} 5$ group. \#\#P $<0.01$ and \#\#\#P $<0.001$ vs. P13 group. 